\title{
Sensors and sensor arrays based on conjugated polymers and carbon nanotubes*
}

\author{
Liming Dai ${ }^{\ddagger}$, Prabhu Soundarrajan, and Taehyung Kim \\ Department of Polymer Engineering, College of Polymer Science and Polymer \\ Engineering, University of Akron, Akron, OH 44304-2909, USA
}

\begin{abstract}
The need for cheaper, faster, and more accurate measurements has been a driving force for the development of new sensing devices. As is well known, the electrical conductivity of conjugated polymers can be reliably regulated over a wide range through interactions with electron acceptors and donors. This, together with the fast optical dynamics (either in the ground or excited states) of most conjugated polymers, has made conjugated polymers very attractive as transducer-active materials. On the other hand, the unusual electronic, mechanical, and thermal properties of carbon nanotubes have also led to their potential use in a wide range of devices, including sensors. In particular, the ability of carbon nanotubes and their derivatives to operate as gas and glucose sensors has been recently demonstrated. This article provides a status review on the research and development of sensors and sensor arrays based on conjugated polymers and carbon nanotubes. The unique features characteristic of most reported sensing transduction modes related to conjugated polymers and carbon nanotubes are discussed, along with their pros and cons.
\end{abstract}

\section{INTRODUCTION}

Measurement represents one of the oldest methods used by human beings to better understand and control the world. Chemical and biological sensors (or biosensors) are the evolved products of physical measurement technologies. In fact, chemical sensors are measurement devices that convert a chemical or physical property of a specific analyte into a measurable signal, whose magnitude is normally proportional to the concentration of the analyte. In this context, biosensors are a subset of chemical sensors that employ a biological sensing element connected to a transducer to recognize the physicochemical change and to produce the measurable signal from particular analytes, which are not necessary to be biological materials themselves, although sometimes they are. On the basis of the transduction principle, chemical and biological sensors can be classified into three major classes with different transducers: sensors with electrical transducers, sensors with optical transducers, and sensors with other transducers (e.g., mass change) [1].

Conjugated polymers with alternating single and double carbon-carbon bonds have been demonstrated to possess interesting optoelectronic properties through a continuous overlapping of $\pi$-orbitals along the polymer backbone and its interaction with electron acceptors or donors [1]. The unusual electronic and optical properties of conducting polymers have made them very attractive as transduceractive materials in various sensing devices. Having a conjugated all-carbon structure with a unique molecular symmetry, carbon nanotubes also show interesting electronic, photonic, mechanical, and

*Pure Appl. Chem. 74, 1489-1783 (2002). An issue of reviews and research papers based on lectures presented at the $2^{\text {nd }}$ IUPAC Workshop on Advanced Materials (WAM II), Bangalore, India, 13-16 February 2002, on the theme of nanostructured advanced materials.

${ }^{\ddagger}$ Corresponding author: E-mail: ldai@uakron.edu 
thermal properties [2]. With so much significant advancement in both material science and device fabrication technology within the last decade or so, the turn of this century witnessed the evolution of early chemical and biological sensors developed in the 1980s into more complex measurement devices of capabilities for various sophisticated analyte detections. Furthermore, the recent development of sensor arrays is revolutionizing the way in which many chemical and biomedical tests are performed in both research and clinical diagnostic laboratories. In this paper, we will illustrate these developments by presenting an overview of the recent research and developments on various sensors and sensor arrays based on conjugated polymers and carbon nanotubes.

\section{CONJUGATED POLYMER SENSORS}

\section{Conjugated polymer sensors with electrical transducers}

Owing to their interesting optoelectronic properties, conjugated polymers have been studied as a major class of sensing elements for the development of sensors with electrical or optical transducers. The electrical transducer system can be further divided into, at least, four basic electrical transduction modes: (i) conductometry: monitoring the conductivity changes; (ii) potentiometric: monitoring the open circuit potential at zero current; (iii) amperometry: monitoring the change in current while the potential is kept constant; and (iv) voltammetry: monitoring the change in current while varying the applied potential. The fundamental principles, pros and cons for each of the electrical transduction modes are discussed below by presenting some selected examples.

\section{Conjugated polymer conductometric sensors}

Conductometry is the most commonly used sensing method, in which the change in conductivity of the device is measured. (Conductivity is the reciprocal of resistivity, which is given by $\rho=\mathrm{RS} / 1$ with $\mathrm{R}, \mathrm{S}$, and 1 being resistance, sample area, and thickness, respectively. For convenience, however, the resistivity and resistance are used as the same in this article, as are conductivity and conductance.) Many processes that lead to changes in carrier density or mobility will cause changes in conductivity. The interaction of conjugated polymers with electron acceptors or donors in particular causes changes in both carrier density and mobility, leading to more significant changes in conductivity. The early work on the conductivity measurements of polyacetylene films upon doping with vapors of iodine, bromine, or $\mathrm{AsF}_{5}$, and subsequent compensation with $\mathrm{NH}_{3}$ constitutes the simplest conducting polymer gas sensors [3]. Indeed, metal (e.g., copper or palladium)-doped electrodeposited polypyrrole and poly-3methylthiophene films have recently been used for the detection of reducing gases such as $\mathrm{NH}_{3}, \mathrm{H}_{2}$, and $\mathrm{CO}$.

Besides, the interaction of a doped conjugated conducting polymer (e.g., HCSA-doped PANI-EB) with certain organic solvents (e.g., $m$-cresol) could cause a conformational transition of the polymer chain from a "compact coil" to an "expanded coil" through the so-called "secondary doping" process, which was found to be accompanied by a concomitant change in conductivity (Fig. 1) [4]. The conformation-induced conductivity changes, either an increase or a decrease in conductivity, have also been observed when conjugated conducting polymers were exposed to some common organic vapors [methanol, hexane, chloroform, tetrahydrofuran (THF), benzene, toluene, acetone, etc.], providing the basis for developing conjugated conducting polymer-based sensors for the detection of hydrocarbon vapors [5].

Figure 1a shows the response of a dodecylbenzenesulfonate acid-doped polypyrrole, spin-cast on a gold interdigitated electrode, to toluene vapor. As can be seen, about $5 \%$ change in resistance was observed in each cycle with a short response time and good reversibility.

Figure $1 \mathrm{~b}$ shows the percentage changes in resistance for the polypyrrole sensor after exposure to static air saturated with various analytes at room temperature for $5 \mathrm{~s}$ in the consecutive numerical order. Also included in Fig. 1b are the corresponding results for a similar sensor based on polypyrrole (molybate anion) synthesized in the presence of polystyrene (examples 8 and 9 in Fig. 1b). It can be seen that 


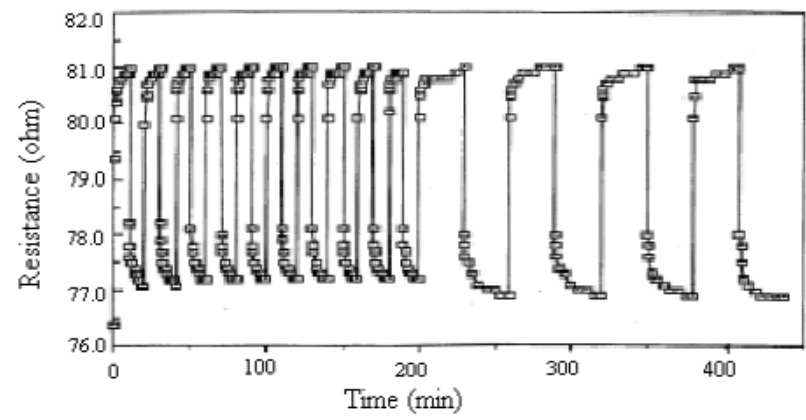

(a)

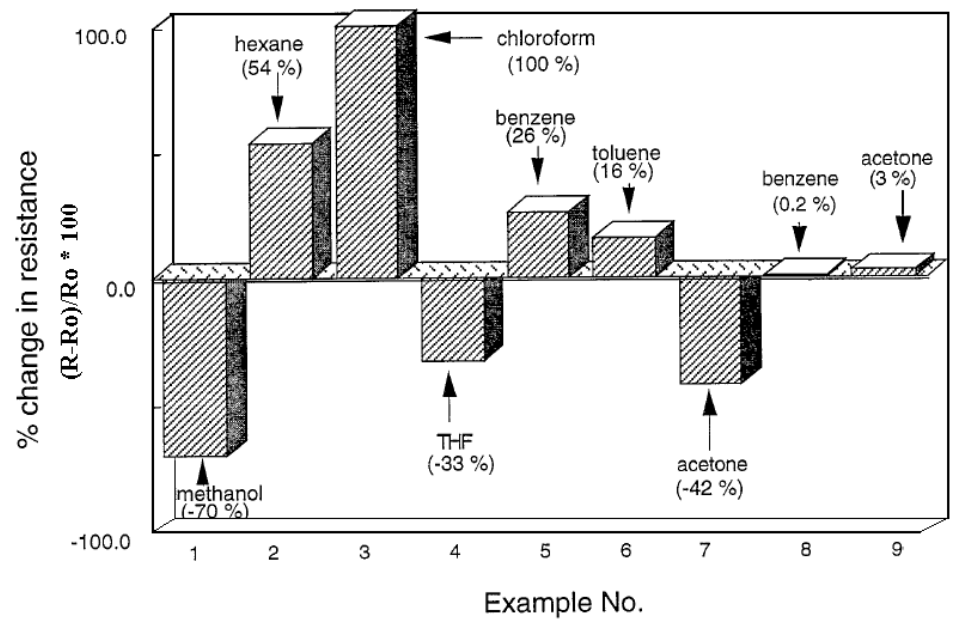

(b)

Fig. 1 (a) Response of a conducting polypyrrole-based sensor to a stream of $\mathrm{N}_{2}(1500 \mathrm{ml} / \mathrm{min})$ saturated with toluene vapor at $0{ }^{\circ} \mathrm{C}$ (partial pressure of toluene, 6.8 Torr) passing over the sensor for 10-min intervals, followed by a $1500 \mathrm{ml} / \mathrm{min}$ stream of pure $\mathrm{N}_{2}$ for 10-min intervals. The results are given for the first 10 complete 20-min cycles and subsequent cycles with a cycle time of $60 \mathrm{~min}$. (b) Percentage change in resistance of doped polypyrrole sensors on exposure to air saturated with various analyte vapors at room temperature, where $\mathrm{R}_{0}$ and $\mathrm{R}$ are resistance of the sensor before and after 5-s exposure to the analyte/air mixture, respectively. (After ref. 5 with copyright permission.)

the sensory response to a given analyte vapor depends strongly on the nature of the dopant anions associated with the conducting polymer, whereas the same sensor can give a large degree of changes (either increase or decrease) in resistance with different analyte vapors. These results clearly indicate conjugated conducting polymers are promising for sensing air-borne volatile organic compounds, such as alcohols, ethers, esters, halocarbons, $\mathrm{NH}_{3}$ (electron donor), $\mathrm{NO}_{2}$ (electron acceptor), and even certain warfare agent stimulants.

\section{Conjugated polymer potentiometric sensors}

Potentiometric transduction mode is a very simple form of sensing, in which the conducting polymer serves as a sensing membrane and changes in the open-circuit potential (i.e., an electrochemical cell potential at zero current) are measured as the sensor signal. The concerned changes in the open-circuit potential, in turn, are mainly resulted from shifts in the "dopant" anion equilibrium within the polymer film caused by either changes in the solution concentration of dopant anions or ion exchange of the "dopant" anion within the polymer film with other ions in the test solution, or both. Since the conduc- 
tivity of conjugated conducting polymers may span the range from insulator through semiconductor to metal, the potentiometric response to small changes in anion or cation concentration depends strongly on the starting redox composition of the polymer electrode. This is a major drawback for this simple transduction mode.

Using electropolymerized poly(thienylpyrrole), PTP, Oubda et al. [6], have constructed miniaturized potentiometric sensors for both in vitro and in vivo sensing of $\mathrm{pH}$ and glucose. In particular, these authors demonstrated that the conjugated conducting polymer-coated microelectrodes with entrapped glucose oxidase exhibited linear behavior up to $20 \mathrm{mM}$ glucose with short response times. Similarly, a linear relationship between the open-circuit potential and $\mathrm{pH}$ with a slope of $60 \mathrm{mV} / \mathrm{pH}$-unit at $37^{\circ} \mathrm{C}$ was observed for a PTP-coated microelectrode used for $\mathrm{pH}$ sensing. The response time of the $\mathrm{pH}$ sensor was found to be within seconds.

\section{Conjugated polymer amperometric sensors}

In amperometric sensors, the signal is derived from changes in an electrochemical cell current with the change of analyte concentration under an impressed constant voltage on the polymer-modified electrode. In this case, the conjugated conducting polymer may play either an active role by participating in mediation of the redox process or a passive role when the polymer merely provides a site for anchoring an enzyme or other redox-active probe molecules. The use of pulsing techniques such as DC pulsed amperometry and $\mathrm{AC}$ impedance techniques allows kinetic measurements, while the use of current integration to yield a coulometric response can enhance weak signals, but generally does not improve the signal-to-noise ratio.

Through sequential electrochemical polymerization of pyrrole or pyrrole derivatives (e.g., $\omega$-carboxyalkylpyrrole) entrapped with tyrosinase (a copper-containing tetrameric enzyme that catalyzes the oxidation of phenolic compounds), Kranz et al. [7] have constructed multilayer amperometric biosensors for the determination of phenolic compounds. The multilayer structure allows, in principle, to regulate the sensor properties, for example, by sequentially controlling the diffusion of interfering compounds, the immobilizing of enzymes, and the electron-transfer pathways between adjacent layers.

\section{Conjugated polymer voltammetric sensors}

Voltammetric sensors generate the sensing response from the redox peak current characteristic of the analyte under a sweep of the electrode voltage over a range of redox potentials associated with the target redox reaction. As is the case in amperometric sensors, the conjugated conducting polymer in the voltammetric sensors may act either as a redox-active material to reduce the redox potential for the analyte of interest, and hence reduce the influence of background and interfering currents, or merely as the substrate for immobilizing a redox mediator molecule. Unlike the amperometric sensors, however, the voltammetric sensors offer an additional advantage with which redox signals for reference molecules added to the sample can be simultaneously measured to improve accuracy.

Based on the measurements of the NO oxidation current, Fabre et al. [8], have demonstrated voltammetric detection of $\mathrm{NO}$ in the rat brain with a carbon fiber electrode coated by conjugated conducting polymer and Nafion bilayer films. A linear relationship between the oxidation current and the NO concentration in solution was observed over a wide range from $10^{-7}$ to $10^{-3} \mathrm{M}$ with a very high sensitivity. This type of sensor has been implanted in the rat brain to detect the NO release in real time and cross-checked by injecting the rat with a NO-synthase inhibitor. Owing to their large surface area, excellent electronic properties, as well as good mechanical and environmental stability, aligned carbon nanotubes may well work better than the carbon fibers for this approach.

\section{Conjugated polymer sensors with optical transducers}

\section{Conjugated polymer fluorescent ion chemosensors}

As the recognition of the possible effects of metal (e.g., certain transition- and post-transition-metal ions) is of paramount importance to human health [9], there has been considerable effort directed 
toward the design and development of chemosensors for metal ions. The development of metal ionselective chemosensors based on low-molecular compounds (e.g., crown ether derivatives) that selectively respond to the presence of specific metal ions through an electrochemical (e.g., redox potential) or optical (e.g., absorption or fluorescence) change, for example induced by the host-guest inclusion, has for decades been an active research area [10-14]. Research on polymeric metal-selective chemosensors, however, is a relatively recent development $[15,16]$. Compared with small molecular monoreceptor systems, polymeric chemosensors offer important advantages in signal amplification via the multisite receptor-analyte interactions.

\section{Scheme 1}

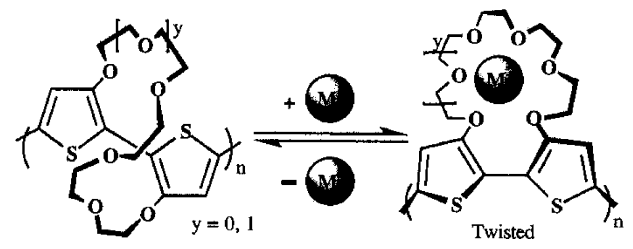

By substituting crown-ether macrocycles into the regiospecific polythiophene backbone, Marsella and Swager [17] have developed chemosensors for sensing alkali metal ions. Since crown-ether prefers to distribute the constituent oxygen atoms uniformly around a guest metal ion, the ion coordination with the crown-ether-substituted polythiophene could cause conformational changes of the polymer backbone (Scheme 1), providing both the electrical and optical transduction modes [17].

Furthermore, the ring size of the macrocycle substitutes was found to play an important role in regulating the selectivity for metal ions. For instance, the relatively small $\mathrm{Na}^{+}$ions caused larger optical effects to polymer 1 (91 nm blue shift) and $\mathbf{2}(63 \mathrm{~nm})$ substituted by 15 -crown-5 rings (Scheme 2$)$ than $\mathrm{K}^{+}$ions, for which the blue shift was considerably smaller. In contrast, polymer 3 with 18-crown6 analogs (Scheme 2) showed a larger blue shift for $\mathrm{K}^{+}(45 \mathrm{~nm})$ than for $\mathrm{Na}^{+}(30 \mathrm{~nm})$.

Scheme 2

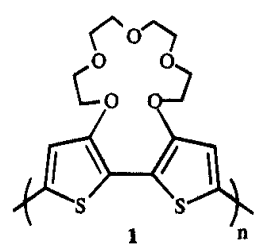

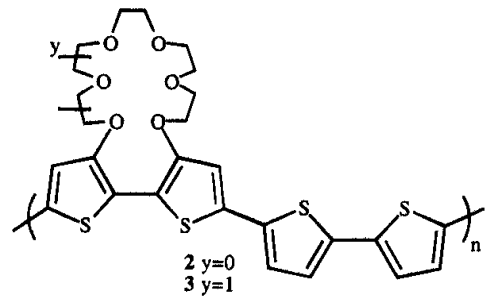

Based on these findings, Swager and coworkers [18] used calix[4]arene with highly organized arrangement of oxygen atoms as a more specific scaffold for the design of ionophores. In this study, the absorption and emission characteristics of a conjugated poly(phenylene bithiophene), $\mathbf{4}$, and a monomeric model compound, 5 (Scheme 3), were investigated as a function of $\left[\mathrm{Li}^{+}\right],\left[\mathrm{Na}^{+}\right],\left[\mathrm{K}^{+}\right]$, and $\left[\mathrm{Ca}^{2+}\right]$.
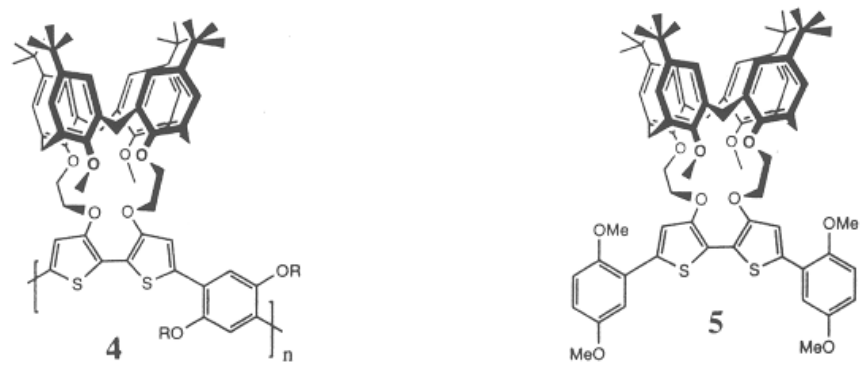

Scheme 3 


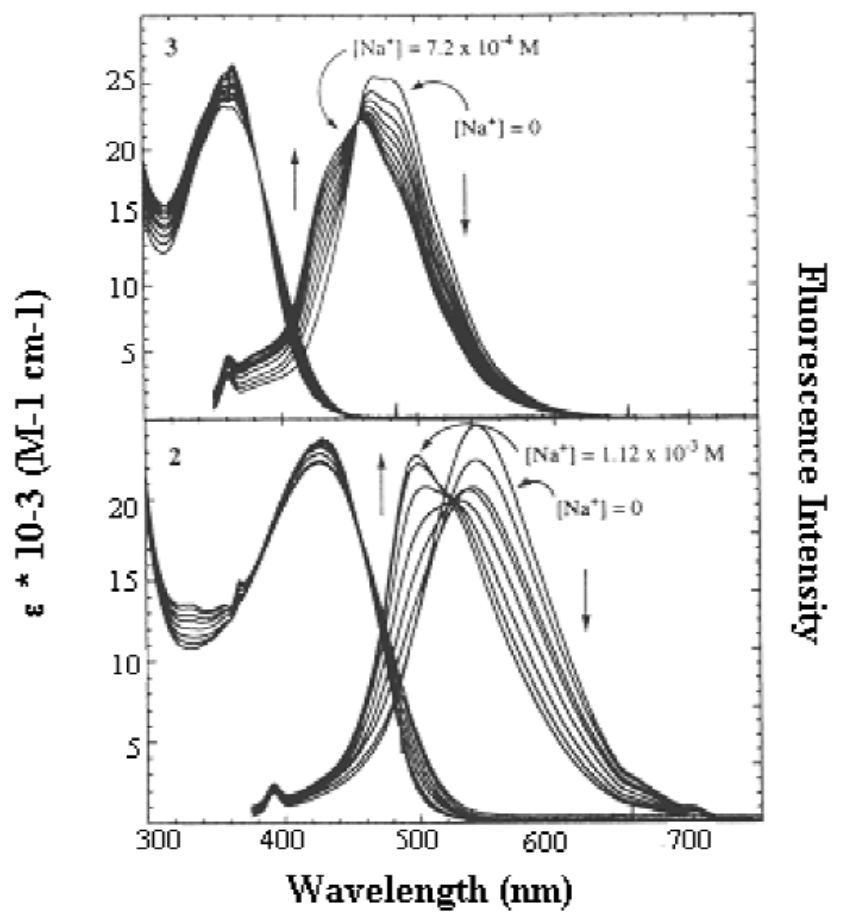

Fig. 2 Adsorption and emission spectra of the model compound 5 (top) and polymer 4 (bottom) as a function of increasing $\left[\mathrm{Na}^{+}\right]$. For $4,\left[\mathrm{Na}^{+}\right]$increased from $0 \mathrm{M}$ to $1.12 \times 10^{-3} \mathrm{M}$ in increments of $1.6 \times 10^{-4} \mathrm{M}$ and $\lambda_{\text {ex }}=$ $350 \mathrm{~nm}$. For 5, $\left[\mathrm{Na}^{+}\right]$increased from 0 to $7.2 \times 10^{-4} \mathrm{M}$ in increments of $8 \times 10^{-5} \mathrm{M}$ and $\lambda_{\text {ex }}=320 \mathrm{~nm}$. (After ref. 18 with copyright permission.)

In particular, these authors found that the calix[4]arene bithiphene receptor in both $\mathbf{4}$ and $\mathbf{5}$ provides selectivity for $\mathrm{Na}^{+}$as the addition of $\mathrm{Na}^{+}$reduces the Stokes shift, whereas $\mathrm{Li}^{+}, \mathrm{K}^{+}$, or $\mathrm{Ca}^{2+}$ does not affect their absorption and emission characteristics.

As seen in Fig. 2, the polymer 4 showed a larger shift in the emission than that for the model compound $\mathbf{5}$ in response to $\mathrm{Na}^{+}$due to the multiple binding sites that are present in the former, but absent in the latter.

Apart from the aforementioned fluorescent ion chemosensors that involve metal ligation with individual conjugated polymer chains, Swager and coworkers [19] have also developed chemosensors based on the interchain interactions of conjugated polymers. In particular, these authors synthesized the poly(p-phenylene ethynylene)s, 6-9 (Scheme 4), and exploited a new transduction mechanism related to the aggregation of crown-ether-substituted conjugated polymers induced by $\mathrm{K}^{+}$ions (Scheme 5 ).

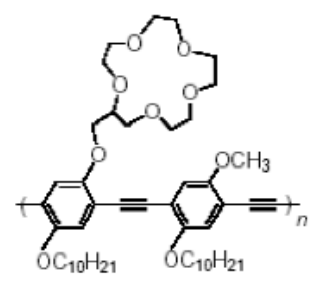

$1 M_{\mathrm{n}}=19600 \mathrm{PDI}=2.5$

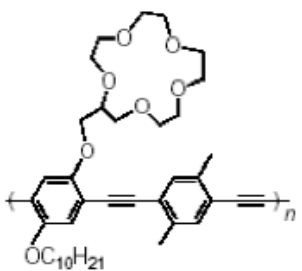

$\begin{aligned} 2-\mathrm{S} M_{\mathrm{n}} & =4700 \mathrm{PDI}=3.1 \\ 2-\mathrm{L} M & =36000 \mathrm{PDI}=3.2\end{aligned}$

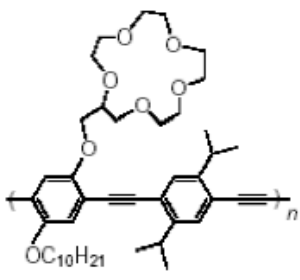

$3 M_{\mathrm{n}}=66000 \mathrm{PDI}=1.9$

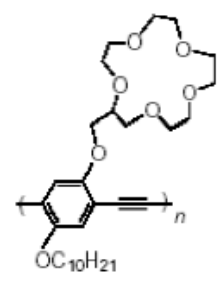

$4 M_{\mathrm{n}}=8100 \mathrm{PDI}=2.0$

Scheme 4 


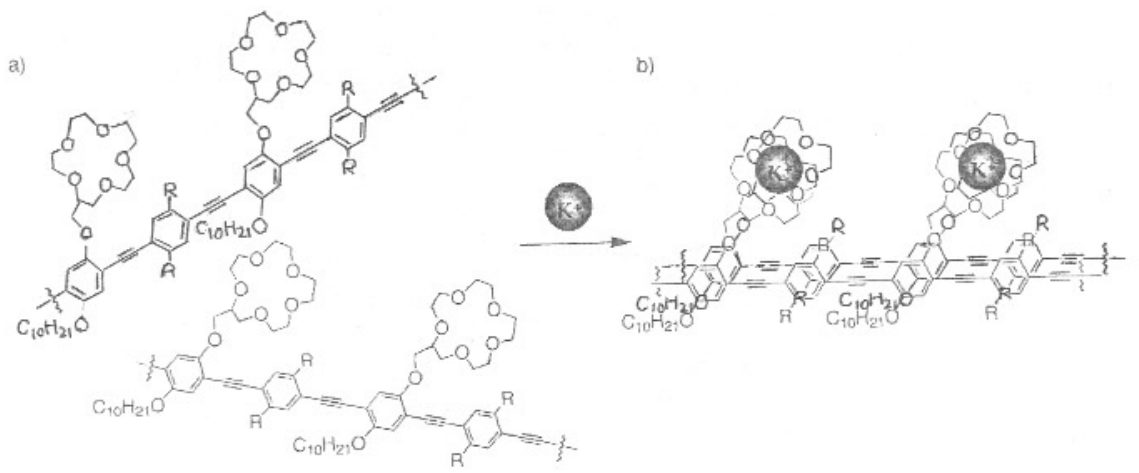

\section{Scheme 5}

It was found that this new sensory system displayed a high selectivity for $\mathrm{K}^{+}$over $\mathrm{Na}^{+}$with an enhanced sensitivity due to the interchain energy transfer. The observed high selectivity for $\mathrm{K}^{+}$arises from the fact that while $\mathrm{K}^{+}$ions induce the polymer aggregation via the well-known 2:1 sandwich complex between $\mathrm{K}^{+}$ions and [15]crown-5, as shown in Scheme 5, $\mathrm{Na}^{+}$ions (also $\mathrm{Li}^{+}$) cannot do so, owing to the formation of 1:1 complex with [15]crown-5 [20].

As shown in Fig. 3, the addition of $\mathrm{K}^{+}$ions into a polymer $\mathbf{7}$ solution in THF produced a new redshifted peak at $459 \mathrm{~nm}$ in the absorption spectra and caused a significant decrease in fluorescence emissions owing to the fluorescent quenching associated with the ion-specific aggregation. The sensory responses, in terms of the relative percentage of fluorescence quenching, to $\mathrm{K}^{+}, \mathrm{Na}^{+}$, and $\mathrm{Li}^{+}$clearly show a high sensitivity and selectivity.

To prove that the sensory response indeed resulted from the interpolymer $\pi$-stacking aggregations, Swager and coworkers [19] have further prepared a monolayer LB film of polymer 7 on a hydrophobic substrate. They found that the changes in the absorption and fluorescence spectra in response to $\mathrm{K}^{+}$for the LB film were the essentially same as for solutions (Figs. 3a and 3b).

The effectiveness of the interpolymer $\pi$-stacking aggregation depends strongly on the bulkiness of the side-groups grafted onto the polymer backbone. Generally speaking, bulky side-groups will retard the interpolymer aggregation and weaken the response to $\mathrm{K}^{+}$ions. In this context, polymer $\mathbf{6}$ shows a much weaker sensory response than polymer $\mathbf{7}$ as the methoxy oxygen atom bound to the

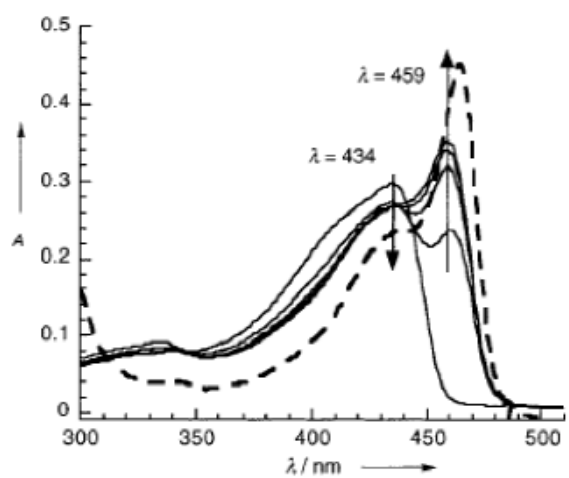

b)

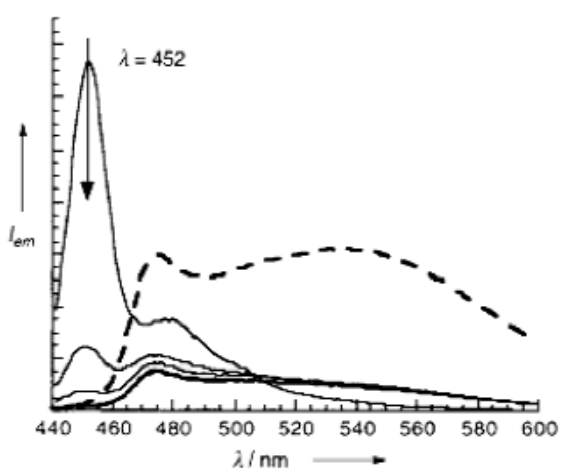

Fig. 3 The evaluation of (a) absorbance and (b) fluorescence spectra of polymer $7\left(2-\mathrm{L}, \lambda_{\mathrm{ex}}=343 \mathrm{~nm}\right)$ with various mole ratios of $\mathrm{K}^{+}$ions. A solution $\mathrm{KPF}_{6}(18 \mathrm{mM})$ in acetonitrile was added gradually into a solution of the polymer $7(5 \mu \mathrm{m}, 3.6 \mathrm{~mL})$ in THF. The arrows indicate the changes for progressively increasing the concentration ratio of $\mathrm{K}^{+}$to $[15]$ crown-5 $=0: 1,0.5: 1,1: 1,2.5: 1,5: 1$, and the dashed lines are corresponding spectroscopic data (arbitrarily scaled for clarity) for a monolayer LB film. (After ref. 19 with copyright permission.) 
phenyl unit in polymer 6 could form a lariat ether-type complexation with [15]crown-5 moieties to compete with the formation of the $2: 1$ sandwich complex. The lack of sensory response to $\mathrm{Na}^{+}, \mathrm{Li}^{+}$, or $\mathrm{K}^{+}$ions for polymer $\mathbf{8}$ can be attributed to the presence of isopropyl groups, which are sufficiently bulky to prevent $\pi$-stacking aggregation with any ion. However, it was no small surprise to find that polymer 9 with [15]crown-5 groups on every repeating unit did not show any response to $\mathrm{Na}^{+}, \mathrm{Li}^{+}$, or $\mathrm{K}^{+}$ions either. The insensitivities of regio-irregular polymer 9 to metal ions is presumably owing to its ability to form intramacromolecular [15]crown-5- $\mathrm{K}^{+}-[15]$ crown-5 bridges, as indicated by molecular modeling studies [19].

\section{Conjugated polymer light-harvesting "turn-on" sensors}

We have so far concerned only "turn-off" type chemosensors, with which the analyte binding leads to a dramatic decrease in the initial fluorescence intensity characteristic of conjugated polymers. By contrast, a sensor that can enhance (turn-on) the fluorescence intensity from an initially low level would be much more sensitive. Using a water-soluble cationic poly ( $p$-phenylene ethynylene), 11, for the multilayer formation with an anionic-polyacrylate-supported $\mathrm{pH}$-sensitive fluoresceinamine (FA) dye, 12, (Scheme 6), Swager and coworkers [21] have constructed a light-harvesting "turn-on" sensor via the layer-by-layer deposition technique through alternate immersion of a glass slide into aqueous solutions of $\mathbf{1 1}$ and $\mathbf{1 2}(1 \mathrm{mg} / \mathrm{mL})$.

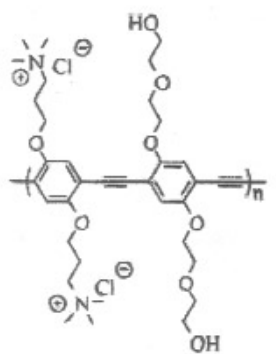

11

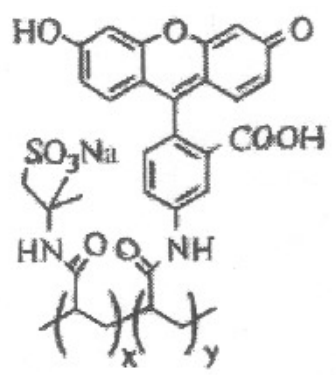

12

\section{Scheme 6}

Since the materials are designed such that the polymer $\mathbf{1 1}$ emission overlaps the absorption peak of the dye 12 (Fig. 4), the fluorescence resonance energy transfer between the polymer and the dye is maximized.

The fluorescence responses for a bilayer sensor composed of one layer of $\mathbf{1 2}$ deposited onto a layer of $\mathbf{1 1}$ immersed in solutions of varying $\mathrm{pH}$ were measured in air on the dried film by selectively exciting conjugated polymer $\mathbf{1 1}$ and FA dye 12 at 420 and $500 \mathrm{~nm}$, respectively.

As shown in Fig. 4b, about $90 \%$ of the emission associated with the conjugated polymer is at $\mathrm{pH} \geq 10$, while the FA's fluorescence is completely lost at $\mathrm{pH}=6$. The almost 10 -fold increase in the FA's emission at $535 \mathrm{~nm}$ when excited at $420 \mathrm{~nm}$ with respect to that measured by direct excitation at $500 \mathrm{~nm}$ seen in Fig. 4b confirms the fluorescence signal amplification through the fluorescence resonance energy transfer process. The reversible fluorescence changes between $\mathrm{pH} 6$ and 11 seen in Fig. 4b clearly indicate an "on-off" fluorescent $\mathrm{pH}$ sensor. Furthermore, it was demonstrated that placing an additional layer of $\mathbf{1 1}$ on top of a bilayer of $\mathbf{1 1}$ and $\mathbf{1 2}$ could result in the formation of a film that responds differently to $\mathrm{pH}$, implying that there was considerable room for tailoring the device performance by controlling the multilayer structure. 


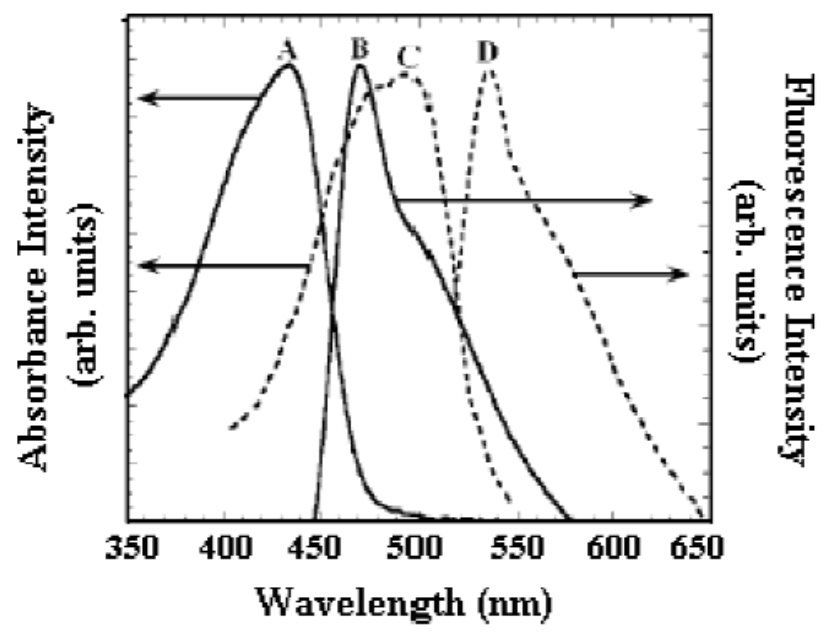

(a)

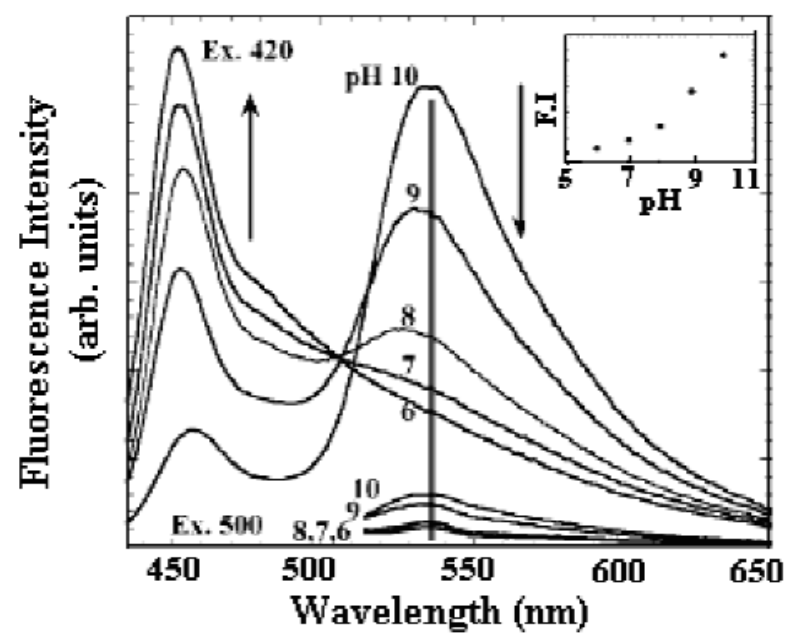

(b)

Fig. 4 (a) Normalized absorbance and emission spectra of polymer 11 and dye 12. Curve A is for the absorbance of a thin film of polymer 11 on glass $\left(\lambda_{e m}=439 \mathrm{~nm}\right)$, and curve $B$ is the corresponding emission spectrum $\left(\lambda_{\mathrm{em}}=471 \mathrm{~nm}, \lambda_{\mathrm{ex}}=420 \mathrm{~nm}\right)$. Curve $\mathrm{C}$ is for the absorbance of a thin film of polymer $\mathbf{1 2}\left(\lambda_{\mathrm{em}}=490 \mathrm{~nm}\right)$, and curve $D$ is the corresponding emission spectrum $\left(\lambda_{\mathrm{em}}=535 \mathrm{~nm}, \lambda_{\mathrm{ex}}=500 \mathrm{~nm}\right.$ ). (b) The fluorescence emission spectra recorded on a 12/11/glass multilayer sensor after dipping into a $0.001 \mathrm{M} \mathrm{KHPO}_{4}$ solution at the denoted $\mathrm{pH}$. The spectra spanning from 435 to $650 \mathrm{~nm}$ and those beginning at $515 \mathrm{~nm}$ were recorded with the excitation wavelength of 420 and $500 \mathrm{~nm}$, respectively. Inset shows the $\mathrm{pH}$-dependence of the emission maximum of the FA band at the excitation wavelength of $420 \mathrm{~nm}$. (After ref. 21 with copyright permission.)

\section{CARBON NANOTUBE SENSORS}

Just as the discovery of $\mathrm{C}_{60}$ has created an entirely new branch of carbon chemistry, the subsequent discovery of carbon nanotubes by Iijima in 1991 opened up a new era in materials science and nanotechnology. Having a conjugated all-carbon structure, fullerene $\mathrm{C}_{60}$ and carbon nanotubes also possess 
interesting optoelectronic properties. In particular, the electronic properties of carbon nanotubes are such that they may be metallic or semiconducting depending on their diameter and the arrangement of graphitic rings in the walls. Besides, they show exceptionally good thermal and mechanical properties. The unique properties of carbon nanotubes have led to their use in areas as diverse as sensors, actuators, field-emitting flat panel displays, energy, and gas storages [22]. The ability of carbon nanotubes and their derivatives to operate as gas sensors has been demonstrated recently [23-25]. As we shall see below, the principles for carbon nanotube sensors to detect the nature of gases and to determine their concentrations are based on change in electrical properties induced by charge transfer with the gas molecules (e.g., $\mathrm{O}_{2}, \mathrm{H}_{2}, \mathrm{CO}_{2}$ ) or in mass due to physical adsorption.

\section{Carbon nanotube gas sensors}

\section{Carbon nanotube sensor for sensing ammonia and nitrogen dioxide}

Dai and coworkers [24] were the first to demonstrate that semiconducting single-wall carbon nanotubes (SWNTs) act as rapid and sensitive chemical sensors at ambient temperature. By doing so, these authors devised a simple sensing system, in which a single semiconducting SWNT was kept in contact with titanium and/or gold metal pads at the two ends (Fig. 5a).

Using the metal pads as the electrodes for electrical measurements, they found that the conductivity of the semiconducting SWNT changed rapidly over several orders of magnitude upon exposure to nitrogen dioxide and ammonia. In particular, an increase in the conductivity by up to three orders of magnitude was observed within $10 \mathrm{~s}$ after exposing the semiconducting SWNT to 200-ppm $\mathrm{NO}_{2}$

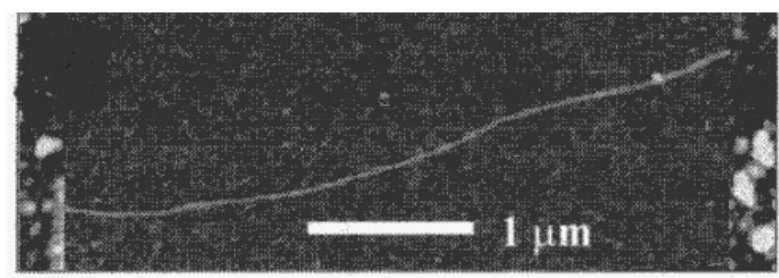

(a)

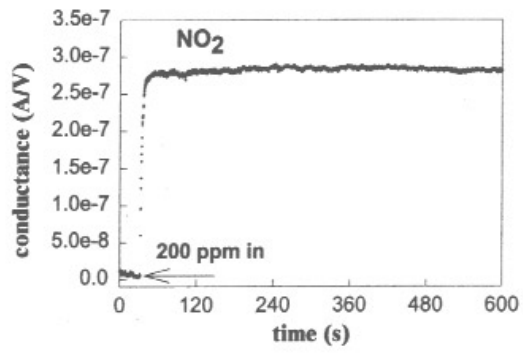

(b)

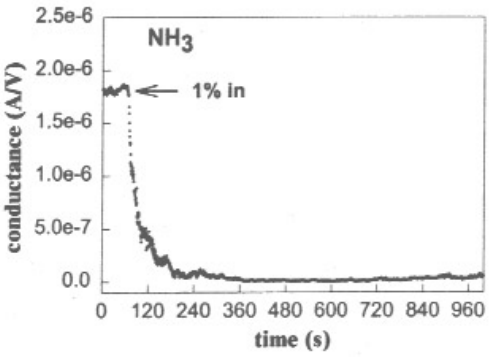

(c)

Fig. 5 (a) Atomic force microscopy image of a metal/SWNT/metal sample used for the gas-sensing application. (b) Electrical conductance response of a semiconducting SWNT to 200-ppm $\mathrm{NO}_{2}$. (c) Electrical conductance response of a semiconducting SWNT to $1 \% \mathrm{NH}_{3}$ vapor. (After ref. 24 with copyright permission.) 
(Fig. 5b), while the conductivity decreased by two orders of magnitude within 2 min upon exposure to $1 \% \mathrm{NH}_{3}$ vapor (Fig. 5c).

These responses were attributed to charge-transfer between the $p$-type (i.e., hole-doped) semiconducting SWNT and electron-donating $\mathrm{NH}_{3}$ or electron-withdrawing $\mathrm{NO}_{2}$ gas. While the latter interaction increased the hole carriers in the SWNT, and hence enhanced conductance, the former interaction had an opposite effect. In principle, the semiconducting SWNT sensors could be applied to many other analytes of electron-donating or -accepting capabilities $\left(\mathrm{I}_{2}, \mathrm{AsF}_{5}, \mathrm{CO}\right.$, etc.). With appropriate surface modification for gaining specific interactions with analytes of biological significance, they could even be used to detect biological elements in solution.

Commercial sensors based on semicoducting metal oxides have been developed for sensing $\mathrm{NO}_{2}$ and $\mathrm{NH}_{3}$, but they need to operate at temperatures of up to $600{ }^{\circ} \mathrm{C}$ for high sensitivity. The SWNT sensor shows strong response, much stronger than is typically recorded for a commercial counterpart, even at room temperature. Besides, the nanotube sensors are relatively easy to make, and their production can be easily scaled up. The nanotube sensors, however, need to take several hours to release the analyte at room temperature before they can be reused. Although the slow recovery of the sensor from the nanotube-analyte interaction can be expedited by heating, it remains a major drawback.

\section{Carbon nanotube hydrogen sensors}

More recently, Dai and coworkers [25] have further demonstrated that certain chemical/physical modification could enhance the molecular specificity of carbon nanotube sensors. In particular, these authors sputter-coated individual and bundled SWNT with Pd nanoparticles. They observed up to $50 \%$ and $33 \%$ decrease in conductivity for the Pd-coated individual SWNT and nanotube bundles, respectively, upon exposure to a flow of air mixed with $400 \mathrm{ppm}$ of hydrogen. This was followed by a rapid recovery of the conductivity after the hydrogen flow was turned off (Fig. 6). The response time, defined as the time required for half of the conductivity change, was found to be about 5 to $10 \mathrm{~s}$, and the time for full recovery was ca. $400 \mathrm{~s}$. The interaction between $\mathrm{H}_{2}$ and the Pd-SWNT is responsible for the sensing mechanism, whereas the corresponding interaction with $\mathrm{O}_{2}$ is the driving force for the recovery process.

As is well known, the interaction of $\mathrm{H}_{2}$ and Pd surface at room temperature could cause atomic hydrogen to dissolve into Pd with a high solubility, leading to a decrease in the work function for Pd [26]. The decrease in Pd work function, in its turn, caused electron transfer from Pd to SWNTs to reduce the hole-carriers in the $p$-type nanotube, and hence a decreased conductivity. The recovery of the nanotube electrical characteristics was made by combining the dissolved atomic hydrogen in Pd with

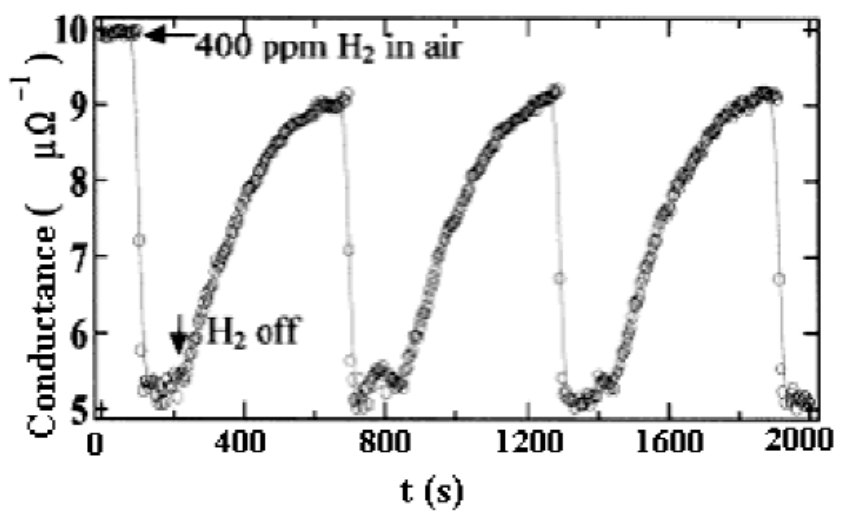

Fig. 6 Electrical conductance of the SWNT coated with Pd nanoparticles vs. time in an air flow with 400-ppm $\mathrm{H}_{2}$ on and off. (After ref. 25 with copyright permission.) 
oxygen in air to form $\mathrm{H}_{2} \mathrm{O}$ when the hydrogen was turned off. The high sensitivity, fast response, and reversibility observed for the Pd-SWNT sensors at room temperature indicate that carbon nanotubes are excellent new sensing materials also for detecting low concentration of molecular hydrogen.

\section{Carbon nanotube oxygen sensors}

In addition to the above studies, Zettl and coworkers [23] reported that SWNTs are extremely susceptible to oxygen adsorption. As shown in Fig. 7a, they found stepwise changes in the electrical resistance up to 10 to $15 \%$ by alternately exposing nanotube samples to air or vacuum at $290 \mathrm{~K}$. Identical changes were observed if pure dry oxygen was used to replace air, indicating that oxygen was responsible for the observed resistance change.

Similar changes were also observed for the thermoelectric power, $S$ [27]. As seen in Fig. 7b, the $S$ was positive with a value of ca. $+20 \mu \mathrm{V} / \mathrm{K}$ for the SWNT in a pure atmospheric pressure of oxygen environment at $350 \mathrm{~K}$. The removal of oxygen from the system caused a continuous change in $S$ from positive to negative, reaching an equilibrium value of ca. $-10 \mu \mathrm{V} / \mathrm{K}$. When the system was alternately cycled between pure oxygen and pure vacuum, a stepwise change in $S$ was obtained. While the negative $S$ indicates that the SWNT is $n$-type semiconductor in vacuum, the oxygen-exposed nanotube with a positive $S$ is $p$-type semiconductor (see the following subsection for more detailed discussions on $S$ ).

Apart from the thermoelectric power measurements discussed above, Collins et al. [23] further used scanning tunneling spectroscopy and transport measurements to confirm that oxygen-exposed SWNTs behave as $p$-type semiconductors and the oxygen's electron affinity could cause these observed changes through charge transfer between the adsorbed oxygen and SWNTs. These results clearly indicate that carbon nanotubes can be used as sensing elements for making new oxygen sensors.

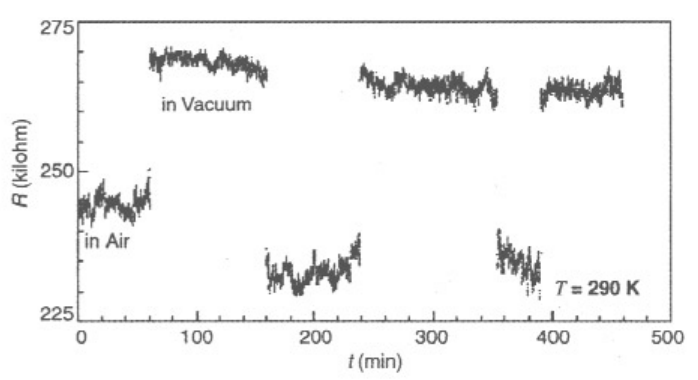

(a)

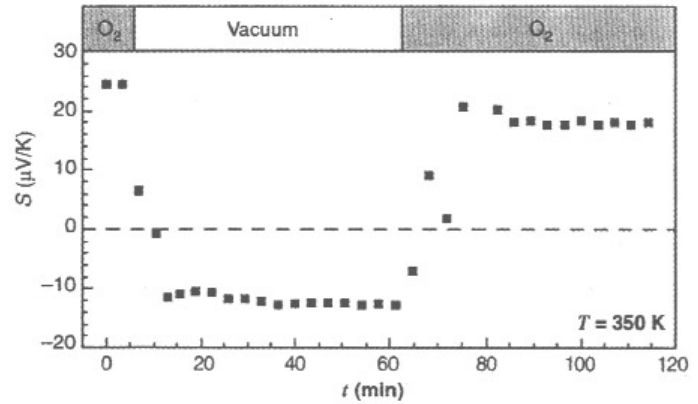

(b)

Fig. 7 (a) Electrical resistance (R) and (b) thermoelectric power responses of SWNT films to gas exposure. (After ref. 23 with copyright permission.)

\section{Carbon nanotube pressure and temperature sensors}

Wood and Wagner [28] have recently found that the disorder-induced Raman peak of SWNTs ( $D^{*}$ band, $2610 \mathrm{~cm}^{-1}$ in air) shifts dramatically upon immersion of the nanotubes in a liquid or measured in a diamond-anvil cell [29] with respect to the corresponding peak observed in air (Fig. 8a). These authors, along with others [30], have further found that the Raman peak of the nanotubes embedded in polymer matrices also shifts significantly with temperature (Fig. 8b). As shown in Fig. 8b, the wave number of the $D^{*}$ band increases with decreasing temperature as the nanotubes experience compression. These changes are highly reversible, indicating the usefulness of carbon nanotubes as molecular sensors for pressure and temperature sensing. 


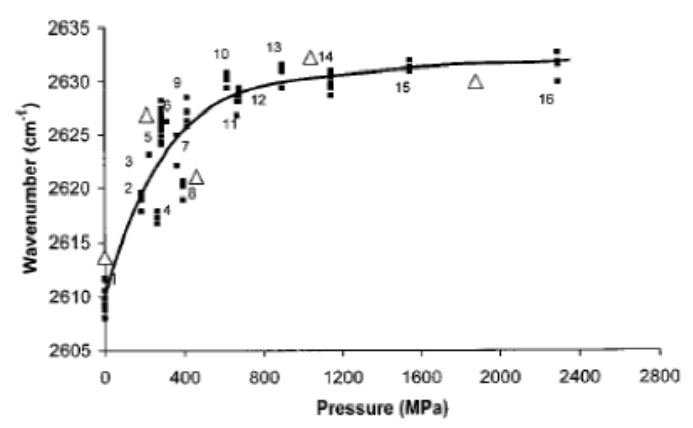

(a)

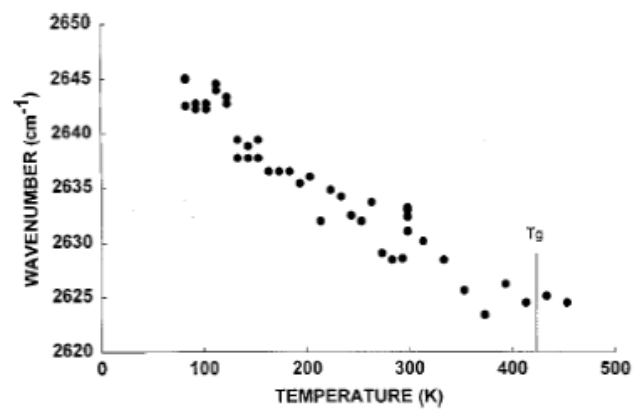

(b)

Fig. 8 The peak position of the $D^{*}$ Raman peak of (a) SWNTs as a function of the molecular (by immersion in liquids, black square) and macroscopic (using a diamond-anvil cell, open triangle) pressure (after ref. 29 with copyright permission), and (b) SWNTs embedded in polycarbonate upon cooling. (After ref. 28 with copyright permission.)

\section{Carbon nanotube chemical force sensors}

Owing to their exceptional electrical and mechanical properties, carbon nanotubes [both SWNTs and multi-walled carbon nanotubes (MWNTs)] have also been used as scanning probe microscope tips with a significantly better lateral resolution compared with commercial $\mathrm{Si}$ and $\mathrm{SiN}$ atomic force microscopy (AFM) tips [31,32]. Although these sharp nanotube tips offer advantages for high-resolution imaging, the unmodified nanotube tips, like most of the commercial tips, do not provide information about the chemical nature of the surface. Lieber and coworkers [33,34] have recently addressed this point by covalently modifying the ends of both SWNT and MWNT tips with chemically and/or biologically active functionalities for chemically sensitive mapping at molecular resolution. For example, these authors have introduced - $\mathrm{COOH}$ groups at the opened end of a SWNT tip by acid oxidation (Fig. 9A) [34]. They then demonstrated the possibility to chemically attach an amine molecule, $\mathrm{RNH}_{2}$ (e.g., benzylamine) onto the terminal $-\mathrm{COOH}$ group through the amide-linkage.

To demonstrate the chemically sensitive force-mapping, Lieber and coworkers [33,34] first used a -COOH-terminated SWNT AFM tip to image a micropatterned surface consisting of $10-\mu \mathrm{m}$ squares of a hexadecanetiol SAM (i.e., $\mathrm{CH}_{3}$-rich surface) surrounded by a 16-mercaptohexadecanoic acid SAM (i.e., -COOH-rich surface). As shown in Fig. 9B(a), the tapping mode image recorded in ethanol shows a greater phase lap for tip- $\mathrm{COOH} / \mathrm{sample-} \mathrm{COOH}$ vs. tip- $\mathrm{COOH} / \mathrm{sample}-\mathrm{CH}_{3}$ regions due to the stronger adhesion force for the former. The corresponding image obtained with the benzylamine-modified SWNT AFM tip shows the patterned feature, but with the opposite phase, contrast Fig. 9B(b), as this particular tip interacts more strongly with the $-\mathrm{CH}_{3}$-rich surface in respect to the $-\mathrm{COOH}$ region. These results clearly demonstrate that chemically modified nanotube AFM tips can be used as sensing probes for chemically sensitive surface recognition. 


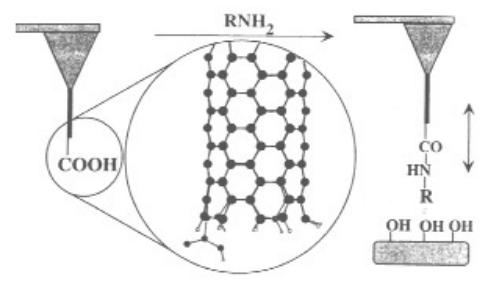

(A)

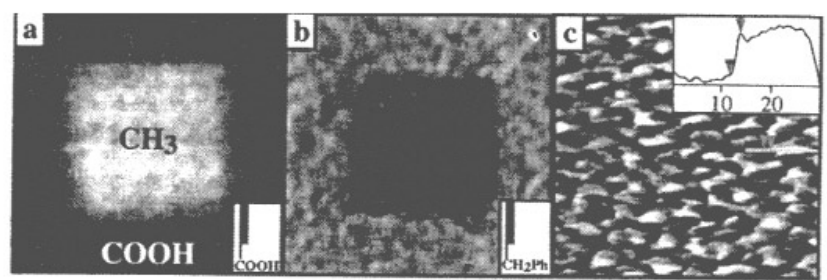

(B)

Fig. 9 (A) Schematic illustrating the SWNT tip modification via coupling an amine $\left(\mathrm{RNH}_{2}\right)$ onto a terminal $-\mathrm{COOH}$ functionality, and the use of the tip-modified nanotube as an AFM probe to sense specific interactions between the functional group (R) and surface -OH group. (B) Tapping mode AFM images of a patterned sample with region-specific $-\mathrm{CH}_{3}$ and $-\mathrm{COOH}$ regions in ethanol recorded with (a) a -COOH-terminated SWNT tip, and (b) a benzylamine-functionalized SWNT tip. Dark regions indicate greater phase lag and the images are $16 \times 16$ $\mu \mathrm{m}$ in size. (c) Tapping mode phase image recorded on a partial bilayer structure, indicating a lateral chemical resolution of ca. $3 \mathrm{~nm}$. (After ref. 34 with copyright permission.)

\section{Carbon nanotube resonator mass sensors}

Frank et al. [36] have measured the conductance of carbon nanotubes by replacing the tip of scanning probe microscope with the nanotube, which forms an electrical circuit with a liquid metal (Fig. 10a).

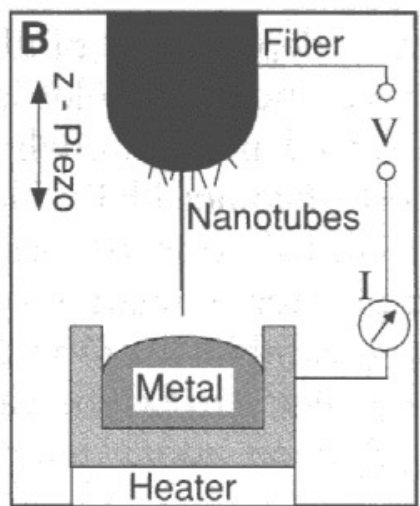

(a)

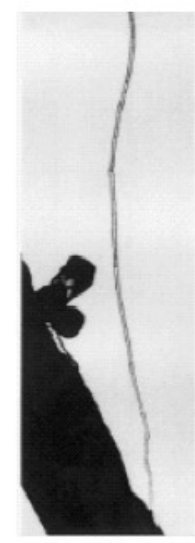

(b)

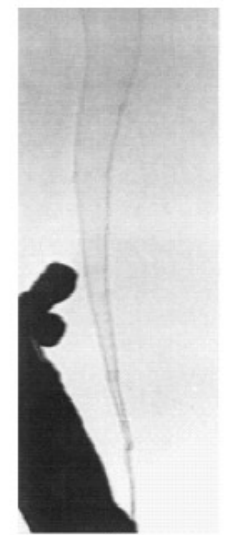

(c)

Fig. 10 (a) Schematic diagram of the measurement of the electrical properties of an individual carbon nanotube. (After ref. 36 with copyright permission.) (b) A carbon nanotube at the stationary and (c) the first resonance mode. (After ref. 37 with copyright permission.) 
They revealed novel stepwise increases in current with increasing voltage, which was attributed to quantum effects.

Using a similar approach, Gao et al. [37] have been able to measure mechanical properties of individual carbon nanotubes. In this case, a transmission electron microscopy (TEM) specimen holder was specially built for applying a voltage across the nanotube and its counter electrode so that the measurements can be done on a specific nanotube whose microstructure is determined by TEM. By applying an alternating voltage with a tunable frequency on the nanotube, resonance can be induced (Figs. 10b and 10c), from which certain mechanical properties of the nanotube can be determined. For example, the bending modulus of the MWNT produced by pyrolysis of FePc was determined to be about $30 \mathrm{GPa}$.

More interestingly, it was found that neither the point defects nor the volume defects caused any significant softening at the local region upon deformation, due to the collectively rippling deformation on the inner arc of a bent nanotube [38]. In analogy to a pendulum, any object attached onto the nanotube could significantly affect the resonance frequency. The mass of the trapped object, down to femtogram ( $1 \mathrm{fg}=10^{-15} \mathrm{~g}$ ), can thus be measured simply by monitoring changes in the resonance frequency.

\section{Carbon nanotube glucose sensors}

Dai and coworkers [39] have recently used the aligned carbon nanotubes produced from FePc to make novel conducting polymer-carbon nanotube (CP-NT) coaxial nanowires by electrochemically depositing a concentric layer of an appropriate conducting polymer uniformly onto each of the constituent aligned nanotubes. The SEM image for the CP-NT coaxial nanowires given in Fig. 11B shows the same features as the aligned nanotube array of Fig. 11A, but with a larger diameter due to the presence of the newly electropolymerized polypyrrole coating in this particular case.

The electrochemical performance of the aligned CP-NT coaxial nanowires was evaluated by carrying out cyclic voltammetry measurements. As for polyaniline films electrochemically deposited on conventional electrodes, the cyclic voltammetric response of the polyaniline-coated nanotube array in an aqueous solution of $1 \mathrm{M} \mathrm{H}_{2} \mathrm{SO}_{4}$ [Fig. $11 \mathrm{C}(\mathrm{a})$ ] shows oxidation peaks at 0.33 and $0.52 \mathrm{~V}$ (but with much higher current densities) [40]. This indicates that polyaniline films thus prepared are highly electroactive. As a control, the cyclic voltammetry measurement was also carried out on the bare aligned nanotubes under the same conditions [Fig. 11C(b)]. In the control experiment, only capacitive current was observed with no peak attributable to the presence of any redoxactive species.

The coaxial structure allows the nanotube framework to provide mechanical stability $[38,39]$ and efficient thermal/electrical conduction [36] to and from the conducting polymer layer. The large surface/interface area obtained for the nanotube-supported conducting polymer layer is an additional advantage for using them in sensing applications. In this context, we have immobilized glucose oxidase onto the aligned carbon nanotube substrate by electrooxidation of pyrrole $(0.1 \mathrm{M})$ in the presence of glucose oxidase $(2 \mathrm{mg} / \mathrm{ml})$ and $\mathrm{NaClO}_{4}(0.1 \mathrm{M})$ in a pH 7.45 buffer solution. Then, the glucose oxidasecontaining polypyrrole-carbon nanotube coaxial nanowires were used to monitor concentration change of hydrogen peroxide $\left(\mathrm{H}_{2} \mathrm{O}_{2}\right)$ during the glucose oxidation reaction by measuring the increase in the electrooxidation current at the oxidative potential of $\mathrm{H}_{2} \mathrm{O}_{2}$ (i.e., the amperometric method). A linear response of the electrooxidation current to the glucose concentration was obtained for the CP-NT nanowire sensor. The linear relationship extends to the glucose concentration as high as $20 \mathrm{mM}$, which is higher than $15 \mathrm{mM}$ typically for the detection of blood glucose in practice [41]. Furthermore, the amperiometric response was found to be about 10 orders of magnitude higher than that of more conventional flat electrodes coated with glucose oxidase-containing polypyrrole films under the same conditions [41]. The CP-NT nanowire sensors were also demonstrated to be highly selective with their amperiometric responses being almost unchanged even in the presence of some interference species including ascorbic acid, urea, and D-fructose. Therefore, the CP-NT nanowires could be used for making new glucose sensors with a high sensitivity, selectivity, and reliability [42]. 


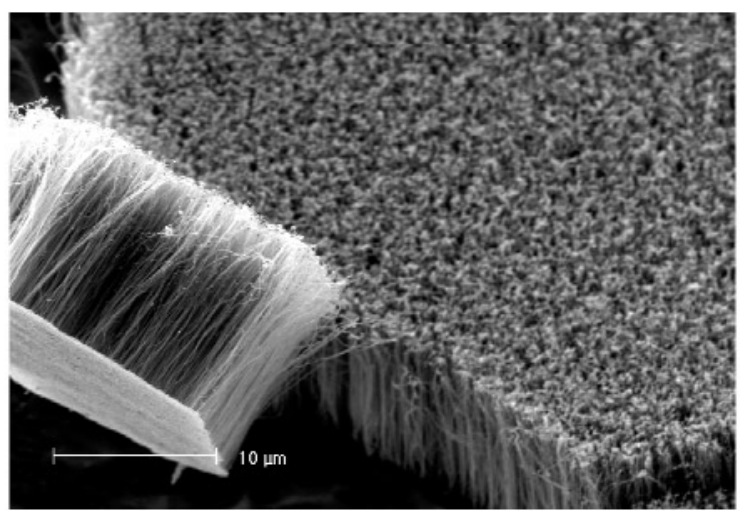

(A)

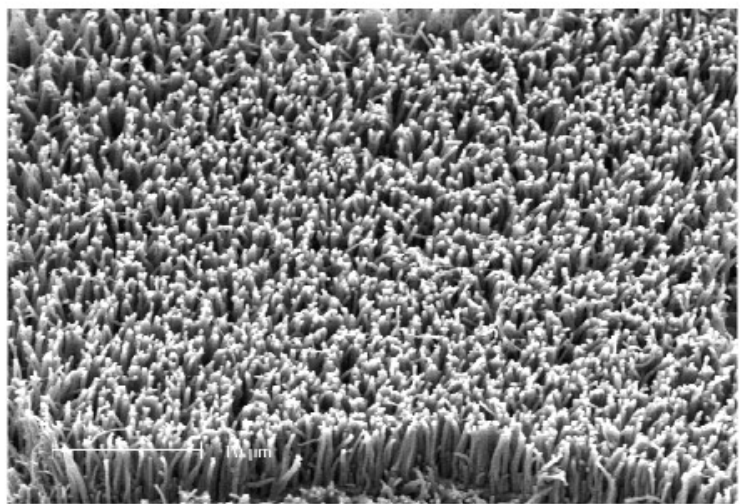

(B)

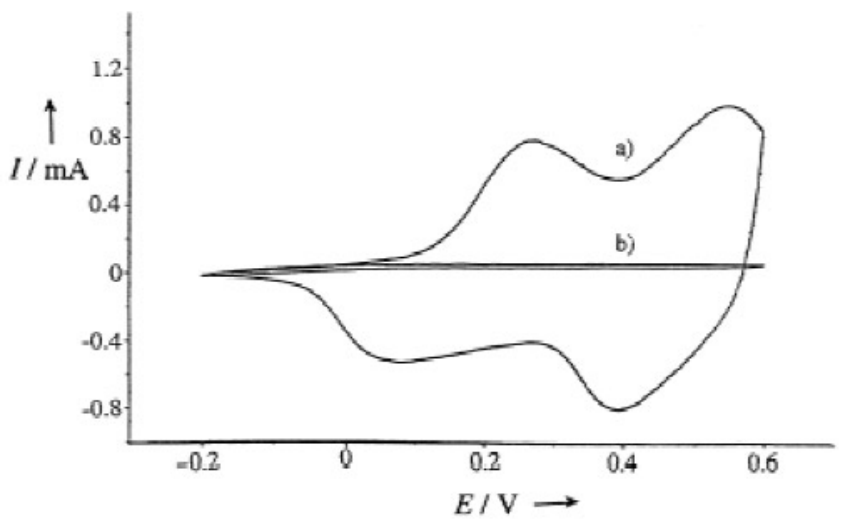

(C)

Fig. 11 (A) Typical SEM images of (a) aligned nanotubes after being transferred onto a gold foil (a small piece of the as-synthesized aligned nanotube film was included, at the left-bottom corner, to show the amorphous carbon layer as well). (B) The CP-NT coaxial nanowires produced by cyclic voltammetry on the aligned carbon nanotube electrode in an aqueous solution of $\mathrm{NaClO}_{4}(0.1 \mathrm{M})$ containing pyrrole $(0.1 \mathrm{M})$. Scan rate: $25 \mathrm{mV} / \mathrm{s}$. (C) Cyclic voltammograms of (a) the polyaniline-coated CP-NT coaxial nanowires and (b) the bare aligned carbon nanotubes. Measured in an aqueous solution of $1 \mathrm{M} \mathrm{H}_{2} \mathrm{SO}_{4}$ with a scan rate of $50 \mathrm{mV} / \mathrm{s}$. (After ref. 39 with copyright permission.) 


\section{Conducting polymer "electronic noses"}

The development of conducting polymer sensor arrays, or electronic nose, based on substituted polypyrrole for gas and odor sensing was first reported by Persaud and Pelosi at the European Chemoreception Congress held in Lyon in 1984 and in a scientific paper in 1985 [43]. This pioneering work generated a great deal of interest among many researchers worldwide and has led to the development of commercial "electronic nose" devices [44].

The manufacture of polymer electronic noses is compatible with many advanced microfabrication technologies, including photolithography, and ink-jet and micro-contact printing. Figure 12a shows a schematic representation of a 32-sensor array formed on a ceramic substrate [45]. As can be seen in Fig. 12a, the active sensing materials (i.e., chemoresistors) were formed between pairs of gold electrodes by electropolymerization of substituted heterocyclic monomers, such as pyrrole, aniline, or thiophene. The

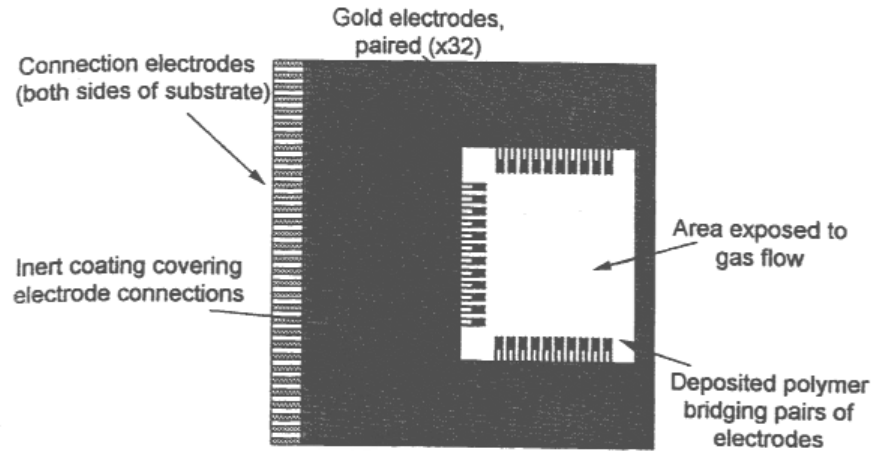

(a)

\section{Bridge structure Sandwich structure}

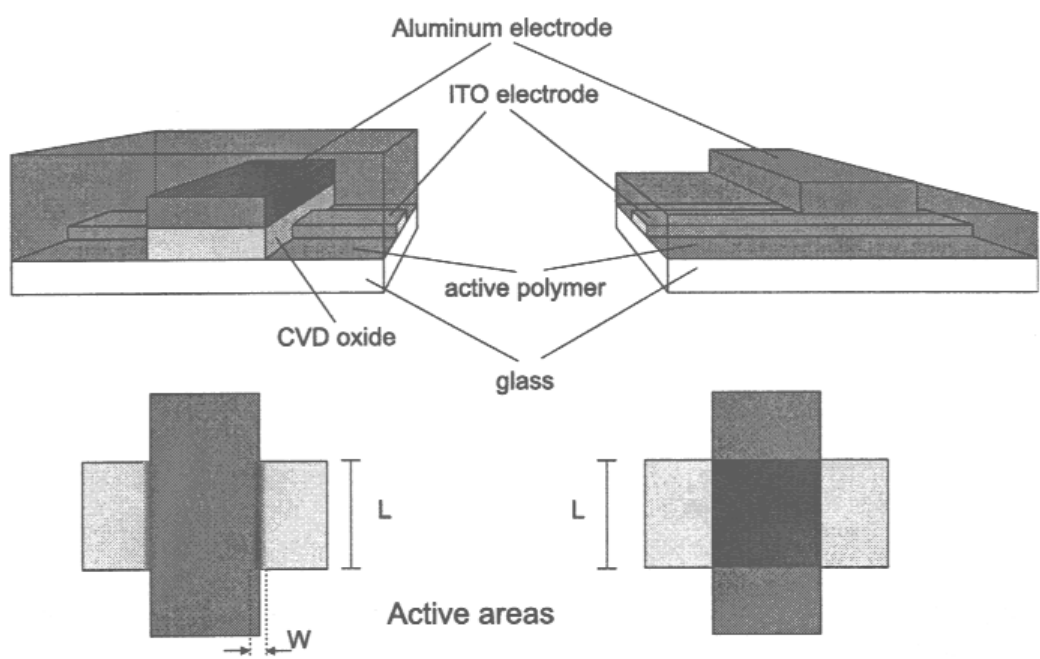

(b)

Fig. 12 (a) Schematic representation of a chip substrate showing the polymer deposited between pairs of electrodes. (After ref. 45 with copyright permission.) (b) A schematic representation of bridge and sandwich structures of the conjugated polymer image sensor arrays. (After ref. 57 with copyright permission.) 
resistance change of the conducting polymer "bridges" is measured as a change in voltage across the sensor at a constant current.

Since the 1984 report on the first electronic nose based on polypyrrole, similar conjugated conducting polymer sensor arrays have been constructed for testing and sensing a wide range of mixture systems, including the odor sensing for gases [46,47], recognition of spoilage bacteria and yeasts in milk [48], water quality control [49], identification of fruit cultivar [50], characterization of wines [51,52], and olive oil [53,54].

To circumvent the instability problem associated with most common conjugated conducting polymers, conductively filled conducting polymers that possess electroactive components for signal transduction and insulating polymers to provide chemical diversity have been used in sensor arrays $[55,56]$. In particular, Lonergan et al. [56] developed an organic vapor sensor array, in which the individual sensor elements consist of carbon black particles dispersed into insulating polymers. This approach offers advantages that the conductive element is very stable carbon black, and that the chemical diversity required for the sensor array can be readily obtained by using different organic polymers as the insulating phase for the carbon black-polymer composites. Sensor arrays were constructed by depositing thin films of such carbon black-organic polymer composites across interdigitate electrodes with each sensing element containing the same carbon black conducting phase but a different organic polymer as the insulating phase. Upon exposure to a vapor mixture, the differing gas-solid partition coefficients for the various polymers of the sensor array produced a pattern of swelling-induced resistance changes that can be used to classify vapors and vapor mixtures. It was found that this type of sensor array could be used to resolve common organic solvents, including molecules of different classes (e.g., aromatics against alcohols) as well as those within a particular class (e.g., benzene vs. toluene or methanol vs. ethanol).

More interestingly, conjugated polymer sensor arrays, coupled with a photodiode, have also been used for optical imaging. In this regard, Pede et al. [57] assembled a photodiode array by coating a bridge microstructure matrix with a conjugated polythiophene/ $\mathrm{C}_{60}$ blend to form an array of pixels between perpendicular electrodes, in which both the upper and lower layers of electrodes were coated with a polymer layer and were separated by an insulating layer at the cross points (Fig. 12b). Then, the bridge devices were used as chemical sensors for detecting the distribution of iodine using a polymer layer that can be oxidized by iodine. This bridge structure has also been used to drive an array of polymer electroluminescent diodes.

Using semiconducting polymers, Yu et al. [58] have also developed large-area, full-color image sensors. These image sensors have a high photosensitivity, low dark current, large dynamic range, and can be fabricated by a simple coating process on flexible or curved substrates at a low temperature. In practice, full-color image sensing in the visible range has been demonstrated by combining a polymer detector array with a set of optical filters. Photosensors in other spectral ranges, UV or near-IR, can also be achieved through proper selection of the sensing material and/or optical filters.

\section{CONCLUDING REMARKS}

Conjugated polymers and carbon nanotubes possess interesting optoelectronic and physicochemical properties that are attractive for their use as transducer-active materials in various sensing devices. While the feasibility of developing chemical and biological sensors based on conjugated polymers and carbon nanotubes for detecting various sophisticated analytes, ranging from gas molecules to glucose, has been clearly demonstrated, the recent research and development of conducting polymer sensor arrays (electronic noses) should, in principle, enable us to identify complex mixture systems even without separation.

Before any large-scale development for certain commercial applications will be realized, however, the environmental instability of conjugated polymers may be still a problem needed to be addressed, as is the cost of carbon nanotubes, although they are both thermally and mechanically sta- 
ble. Further advancement in material science should provide economically viable means for producing advanced conjugated polymer and carbon nanotube composite materials of properties characteristic of both constituent components with interesting synergetic effects. This, coupled with so many micro/nanofabrication methods already reported and more to be developed, will surely lead to the development of sensors and sensor arrays based on conjugated polymers and carbon nanotubes (e.g., sensor arrays from micropatterns of aligned carbon nanotubes and their derivatives with conducting polymer coatings) of practical importance.

\section{REFERENCES}

1. L. Dai, B. Winkler, L. Dong, L. Tong, A. W. H. Mau. Adv. Mater. 13, 915 (2001) and references cited therein.

2. P. Harris. Carbon Nanotubes and Related Structures-New Materials for the Twenty-first Century, Cambridge University Press, Cambridge (1999).

3. J. C. W. Chien. Polyacetylene: Chemistry, Physics and Materials Science, Academic Press, New York (1984).

4. A. G. MacDiarmid and A. J. Epstein. Synth. Met. 69, 85 (1995).

5. A. G. MacDiarmid. Synth. Met. 84, 27 (1997).

6. T. Oubda, P. Zhao, G. E. Nauer. Polym. News 23, 331 (1998).

7. C. Kranz, H. Wohlschlaeger, H.-L. Schmidt, W. Schuhmann. Electroanalysis 10, 546 (1998).

8. B. Fabre, S. Burlet, R. Cespuglio, G. Bidan. J. Electroanal. Chem. 426, 75-83 (1997).

9. E. Foulkes. Biological Effects of Heavy Metals, CRC Press, Boca Raton, Florida (1990).

10. A. W. Czarnik. Fluorescent Chemosensors for Ion and Molecule Recognition, American Chemical Society, Washington, DC (1992).

11. Y. Inoue and G. W. Gokel. Cation Binding by Macrocycles, Marcel Dekker, New York (1990).

12. Y. Nakatsuji, K. Kita, H. Inoue, W. Zhang, T. Kida, I. Ikeda. J. Am. Chem. 122, 6307 (2000).

13. M. H. W. Lam, D. Y. K. Lee, K. W. Man, C. S. W. Lau. J. Mater. Chem. 10, 1825 (2000).

14. L. Prodi, C. Bargossi, M. Montalti, N. Zaccheroni, N. Su, J. S. Bradshaw, R. M. Izatt, P. B. Savage. J. Am. Chem. Soc. 122, 6769 (2000).

15. J. Li and Y. Lu. J. Am. Chem. Soc. 122, 10466 (2000) and references cited therein.

16. T. M. Swager. Acc. Chem. Res. 31, 201 (1998).

17. M. J. Marsella and T. M. Swager. J. Am. Chem. Soc. 115, 12214 (1993).

18. K. B. Crawford, M. B. Goldfinger, T. M. Swager. J. Am. Chem. Soc. 120, 5187 (1998).

19. J. Kim, D. T. McQuade, S. K. McHugh, T. M. Swager. Angew. Chem. Int. Ed. 39, 3868 (2000).

20. G. W. Gokel. Crown Ethers and Cryptands, Royal Society of Chemistry, Cambridge (1991).

21. D. T. McQuade, A. H. Hegedus, T. M. Swager. J. Am. Chem. Soc. 122, 12389 (2000).

22. L. Dai and A. W. H. Mau. Adv. Mater. 13, 899 (2001).

23. P. G. Collins, K. Bradley, M. Ishigami, A. Zettl. Science 286, 1801 (2000).

24. J. Kong, N. R. Franklin, C. Zhou, M. G. Chapline, S. Peng, K. Cho, H. Dai. Science 287, 622 (2000).

25. J. Kong, M. G. Chapline, H. Dai. Adv. Mater. 13, 1384 (2001).

26. A. Mandelis and C. Christofides. Physics, Chemistry and Technology of Solid State Gas Sensor Devices, Wiley, New York (1993).

27. R. D. Barnard. Thermoelectricity in Metal and Alloys, Wiley, New York (1972).

28. J. R. Wood and H. D. Wagner. Appl. Phys. Lett. 76, 2883 (2000).

29. J. Wood, Q. Zhao, M. D. Frogley, E. R. Meurs, A. D. Prins, T. Peijs, D. J. Dunstan, H. D. Wagner. Phys. Rev. B, Condens. Matter. Mater. Phys. 62, 7671 (2000).

30. O. Lourie and H. D. Wagner. J. Mater. Res. 13, 2418 (1998).

31. H. Dai, J. H. Hafner, A. G. Rinzler, D. T. Colbert, R. E. Smalley. Nature 384, 147 (1996).

32. S. S. Wong, J. D. Harper, P. T. Jr. Lansbury, C. M. Lieber. J. Am. Chem. Soc. 120, 603 (1998).

(C) 2002 IUPAC, Pure and Applied Chemistry 74, 1753-1772 
33. S. S. Wong, E. Joselevich, A. T. Woolley, C. Cheung, C. M. Lieber. Nature 394, 52 (1998).

34. S. S. Wong, A. T. Woolley, E. Joselevich, C. Cheung, C. M. Lieber. J. Am. Chem. Soc. 120, 8557 (1998)

35. S. C. Tsang, Y. K. Chen, P. J. F. Harris, M. L. H. Green. Nature 372, 159 (1994).

36. S. Frank, P. Poncharal, Z. L. Wang, W. A. de Heer. Science 280, 1744 (1998).

37. R. Gao, Z. L. Wang, Z. Bai, W. A. de Heer, L. Dai, M. Gao. Phys. Rev. Lett. 85, 622 (2000).

38. P. Poncharal, Z. L. Wang, D. Ugarte, W. A. de Heer. Science 283, 1513 (1999) and references cited therein.

39. M. Gao, S. Huang, L. Dai, G. Wallace, R. Gao, Z. Wang. Angew. Chem. Int. Ed. 39, 3664 (2000).

40. D. Sazou and C. Georgolios. J. Electroanal. Chem. 429, 81 (1997).

41. M. Yasuzawa and A. Kunugi. Electrochem. Commun. 1, 459 (1999).

42. M. Gao, L. Dai, G. G. Wallace. Electroanalysis. In press.

43. K. C. Persaud and P. Pelosi. Trans. Am. Soc. Artif. Organs 31, 297 (1985).

44. J. V. Hatfield, P. I. Neaves, P. J. Hicks, K. C. Persaud, P. Travers. Sens. Actuators B 18, 221 (1994).

45. Y. Osada and D. E. De Rossi (Eds.) Polymer Sensors and Actuators, Springer, Berlin (2000).

46. H. V. Schurmer, P. Corcoran, J. W. Gardner. Sens. Actuators 4, 29 (1991).

47. T. C. Pearce, J. W. Gardner, S. Friel, P. N. Bartlett, N. Blair. Analyst 118, 371 (1993).

48. N. Magan, A. Pavlou, I. Chrysanthakis. Sens. Actuators B 72, 28 (2001).

49. R. M. Stuetz, R. A. Fenner, G. Engin. Water Res. 33, 453 (1998).

50. A. Gelperin, J. L. Dawson, S. M. Cazares, H. S. Seung. In Electron. Noses Sens. Array Based Syst., Proc. Int. Symp. Olfaction Electron. Nose, W. J. Hurst (Ed.), Technomic Publishing, Lancaster (1999).

51. S. Baldacci, T. Matsuno, K. Toko, R. Stella, D. De Rossi. Sens. Mater. 10, 185 (1998).

52. A. Guadarrama, J. A. Fernandez, M. Iniguez, J. Souto, J. A. de Saja. Anal. Chim. Acta 411, 193 (2000).

53. R. Stella, N. Barisci, G. Serra, G. G. Wallace, D. De Rossi. Sens. Actuators B 63, 1 (2000).

54. R. Aparicio, S. M. Rocha, I. Delgadillo, M. T. Morales. J. Agric. Food Chem. 48, 853 (2000).

55. M. S. Freund and N. S. Lewis. Proc. Natl. Acad. Sci. USA 92, 2652 (1995).

56. M. C. Lonergan, E. J. Severin, B. J. Doleman, S. A. Beaber, R. H. Grubbs, N. S. Lewis. Chem. Mater. 8, 2298 (1996).

57. D. Pede, E. Smela, T. Johansson, M. Johansson, O. Inganaes. Adv. Mater. 10, 233 (1998).

58. G. Yu, J. Wang, J. McElvain, A. J. Heeger. Adv. Mater. 10, 1431 (1998). 